\title{
Susanne Gehrmann e Claudia Gronemann (dir.), Les enjeux de l'autobiographique dans les littératures de langue française
}

\section{Ilaria Vitali}

\section{(2) OpenEdition}

\section{Journals}

\section{Edizione digitale}

URL: http://journals.openedition.org/studifrancesi/9680

DOI: $10.4000 /$ studifrancesi.9680

ISSN: 2421-5856

\section{Editore}

Rosenberg \& Sellier

\section{Edizione cartacea}

Data di pubblicazione: 1 décembre 2007

Paginazione: 699

ISSN: 0039-2944

\section{Notizia bibliografica digitale}

Ilaria Vitali, «Susanne Gehrmann e Claudia Gronemann (dir.), Les enjeux de l'autobiographique dans les littératures de langue française», Studi Francesi [Online], 153 (LI | III) | 2007, online dal 30 novembre 2015, consultato il 11 janvier 2021. URL: http://journals.openedition.org/studifrancesi/9680 ; DOI: https://doi.org/10.4000/studifrancesi.9680

Questo documento è stato generato automaticamente il 11 janvier 2021.

\section{cc) $($ ) $\ominus$}

Studi Francesi è distribuita con Licenza Creative Commons Attribuzione - Non commerciale - Non opere derivate 4.0 Internazionale. 


\title{
Susanne Gehrmann e Claudia Gronemann (dir.), Les enjeux de l'autobiographique dans les littératures de langue française
}

\author{
Ilaria Vitali
}

\section{NOTIZIA}

SUSANNE GEHRMANN e CLAUDIA GRONEMANN (dir.), Les enjeux de l'autobiographique dans les littératures de langue française, Paris, L’Harmattan, 2006, pp. 303.

1 Il volume, curato da Susanne Gehrmann e Claudia Gronemann, riunisce diversi studi sugli enjeux della scrittura autobiografica nelle letterature di lingua francese, articolandosi in tre sezioni, ognuna delle quali esamina, da una prospettiva diversa, il rapporto tra le manifestazioni letterarie dell'autobiografia e lo spazio francofono. La prima parte, «Du genre à l'espace autobiographique: le genre occidental comme point de référence», si concentra sulla nuova concezione dell'ibridismo e sui rapporti che esso intesse con l'autobiografia, decostruendo radicalmente la nozione di genere. La seconda parte, «Questionnements et subversions du genre occidental: l'affirmation des écritures postcoloniales», raccoglie diversi interventi sulla specificità del racconto autobiografico in relazione alle problematiche postcoloniali, con particolare attenzione all'area maghrebina e subsahariana, dove «l'autobiographie postcoloniale, entant que discours hybride, s'avère dans ce contexte être une stratégie opérant une transformation des concepts traditionnels de la représentation» (p. 18). La terza ed ultima sezione, "Au-delà du modèle de la représentation: de l'autobiographie postcoloniale à l'hybridité du texte» è infine dedicata agli studi che analizzano l'autobiografia prendendo come punto di partenza la de-costruzione del canone occidentale e il cambiamento dei paradigmi nella rappresentazione socio-culturale. 
2 Tra le aree geografiche maggiormente rappresentate in questo studio, ci sono quelle dei Caraibi - con studi su Confiant, Glissant, Maximin e Chamoiseau - e del Maghreb - con saggi che partono da Isabelle Eberhardt e arrivano fino a Driss Chraibi. La scrittura femminile occupa ampio spazio in questo volume, che conta, fra gli altri, due saggi consacrati all'opera di Assia Djebar, Langue - Corps - Identité. L'écriture autobiographique dans l'œuvre d'Assia Djebar, di Rotraud vON KULESSA, e Vaste est la prison d'Assia Djebar ou l'autobiographie impossibile, di Najiba REGAÏEG. Anche l'Africa nera è rappresentata attraverso l'intervento di Susanne GEHRMANN che affronta l'opera della scrittrice Ken Bugul, Constructions postcoloniales du Moi et du Nous en Afrique: l'exemple de la série autobiographique de Ken Bugul.

3 Les enjeux de l'autobiographique dans les littératures de langue française non si limita a consolidare prospettive di studio acquisite, ma apre la strada a nuovi orizzonti di critica e di lettura. 